\title{
Scaling Up Parenting Interventions is Critical for Attaining the Sustainable Development Goals
}

\author{
Matthew R. Sanders ${ }^{1}$ (D) Gauri Divan ${ }^{2} \cdot$ Meghna Singhal $^{1,2} \cdot$ Karen M. T. Turner $^{1} \cdot$ Richard Velleman $^{2,3}$. \\ Daniel Michelson ${ }^{4} \cdot$ Vikram Patel $^{2,5,6}$
}

Accepted: 6 April 2021 / Published online: 4 May 2021

(c) The Author(s), under exclusive licence to Springer Science+Business Media, LLC, part of Springer Nature 2021

\begin{abstract}
Of all the potentially modifiable influences affecting children's development and mental health across the life course, none is more important than the quality of parenting and family life. In this position paper, we argue that parenting is fundamentally linked to the development of life skills that children need in order to achieve the United Nations Sustainable Development Goals. We discuss key principles that should inform the development of a global research and implementation agenda related to scaling up evidence-based parenting support programs. Research over the past 50 years has shown that parenting support programs of varied intensity and delivery modality can improve a wide range of developmental, emotional, behavioral and health outcomes for parents and their children. Such findings have been replicated across culturally and socioeconomically diverse samples, albeit primarily in studies from Western countries. We highlight the evidence for the relevance of parenting interventions for attaining the SDGs globally, and identify the barriers to and strategies for achieving their scale-up. The implications of the global COVID-19 pandemic for the delivery of evidence-based parenting support are also discussed.
\end{abstract}

Keywords Sustainable development goals $\cdot$ Child development $\cdot$ Parenting $\cdot$ Evidence-based parenting support

\section{Introduction}

In 2015, more than 190 world leaders committed to 17 United Nations Sustainable Development Goals (SDGs) for ending extreme poverty, fighting inequality and injustice, and addressing problems of climate change. The health and well-being of future generations of children are key to attaining these goals. Children constitute a quarter of the world's population [1] with the majority living in low- and middleincome countries (LMICs). More than $40 \%$ of children in

Matthew R. Sanders

m.sanders@psy.uq.edu.au

1 Parenting and Family Support Centre, School of Psychology, The University of Queensland, Brisbane, QLD 4072, Australia

2 Goa \& New Delhi, Sangath, India

3 Department of Psychology, University of Bath, Bath, UK

4 School of Psychology, University of Sussex, Brighton, UK

5 Department of Global Health and Social Medicine, Harvard Medical School, Boston, USA

6 Harvard TH Chan School of Public Health, Boston, USA
LMICs are at risk of falling behind developmental milestones by the age of 5 years, based on the proxy indicators of poverty and stunting [2]. Positive parent-child relationships in early life can protect against these and other adversities, and exert positive impacts across all areas of development including language and communication, executive function and self-regulation, sibling and peer relationships, academic attainment, and mental and physical health [3]. Projecting such outcomes into later childhood, adolescence and aduldhood, we contend that parenting support programs have vast untapped potential to address many of the SDGs from individual to family, community, and global environmental goals (see Table 1). Clark et al. [4] argued that children and families must be at the centre of collective efforts to ensure that by age 18 , they are optimally healthy, educated, engaged in productive citizenship and act as stewards of the Earth. Yet parenting interventions have been relatively overlooked in the global movement to promote child development, and their potential to address the SDGs is largely untested. This article aims to highlight the evidence for the relevance of parenting interventions for attaining the SDGs globally, and the barriers to and strategies for achieving their scale-up. 


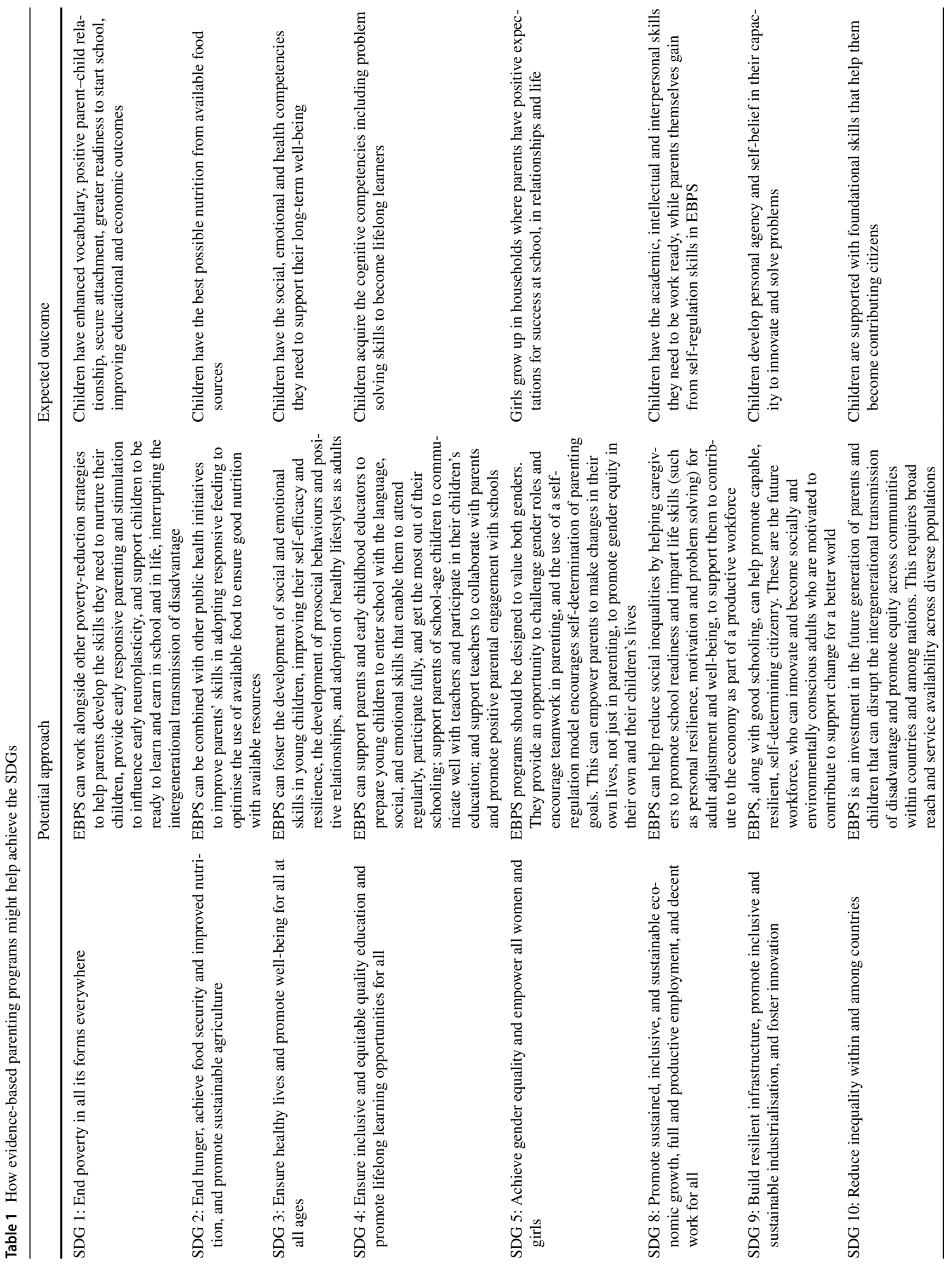


The Influence of Parenting Practices on Child Development and the SDGs

The pervasive influence of parenting on children's development and well-being has been established through longitudinal research and hundreds of parenting intervention trials. Substantial evidence attests to the importance of parenting and the family environment on children's development and life course opportunities. However, parental behavior needs to be understood in the wider ecological framework of both non-modifiable and potentially modifiable determinants that can be influenced through participation in parenting programs (see Fig. 1).

Children are at greater risk of developing serious mental and physical health problems when growing up in harsh, punitive or unpredictable homes characterised by family conflict and violence, abuse and neglect, low levels of positive interaction, insecure attachment, inconsistent discipline, and lack of clear boundaries and limits [5, 6]. Adverse childhood conditions, particularly when they cluster together, cause continuous or intolerable levels of strain, referred to as 'toxic stress'. This stress is toxic in that it impacts not only the metabolic system resulting in higher levels of sugar and inflammation, increasing the risk of diabetes and heart disease in adulthood, but also critically impacts on brain development, particularly affecting the areas responsible for learning and decision making [7].This in turn impacts on the ability of a child exposed to such stresses to achieve their academic and social potential. In addition, children raised in chronically stressful environments are more likely to suffer adverse long-term effects on physical and mental health as adults, and their life expectancy is shorter [6]. Such chronically stressful environments are particularly damaging when both adverse social determinants (e.g., poverty) and negative parenting behaviors co-occur [8].

Protective factors include wider distal societal, environmental and structural factors such as safety and security, policies such as maternity and paternity leave, and stable clean housing and healthy environments [9]. We also know that proximal protective factors within families can buffer adverse social determinants. These protective factors include a predictable environment and the nurturing and responsive care of a responsible caregiver who can not only safeguard a child from adverse experiences and influence the development and strengthening of neural pathways, but actually model and promote key behaviors and skills which build children's resilience and self-regulatory abilities. Protective factors within the family can also protect against withinfamily risks [10]. Parental modelling of social and selfregulatory skills, emotional climate (involving both secure parent-child attachment and positive couple relationships), contingent positive responding, and effective non-violent 


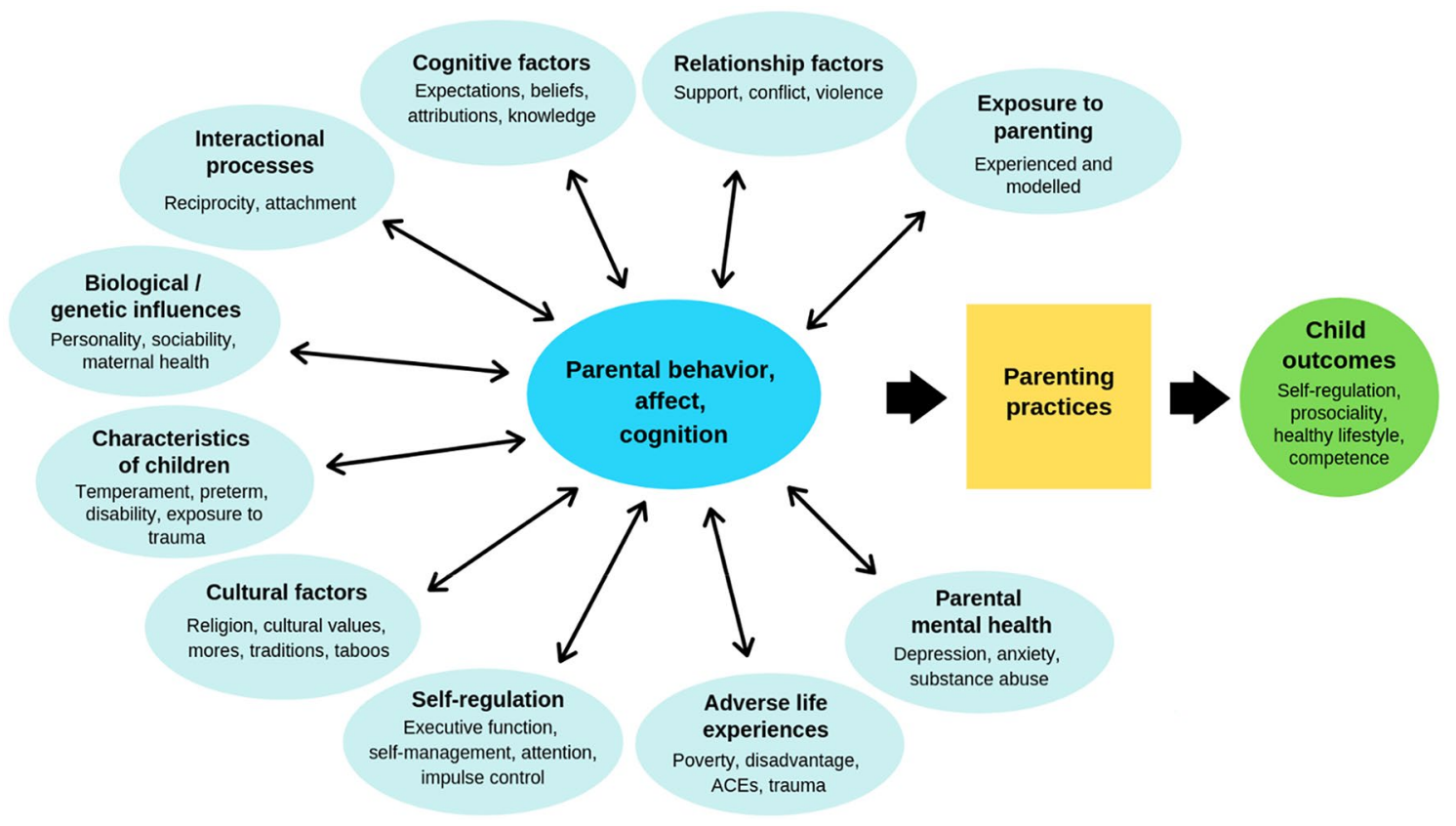

Fig. 1 Non-modifiable and modifiable determinants of parenting and child outcomes

discipline and limit setting $[11,12]$ are key mechanisms by which parenting impacts child development, adult well-being and community connectedness and functioning. Through parents' example, reinforcement, and contingency management strategies, children learn language, social, emotional, and problem solving skills, and to deal with dysregulated emotions such as frustration and anger [8]. The same mechanisms can be activated to promote adult well-being related to the SDGs, such as developing better emotion regulation, anger management and reducing family conflict and genderbased violence. This applies intergenerationally to parents as program participants who learn these skills while imparting and role modelling them to future generations of children.

While the newly launched Nurturing Care Framework by WHO, UNICEF and the World Bank [13] recommends early child development programs as critical to supporting early brain growth and development, this framework also clearly recognises the need to develop a lifecourse approach which supports children and their families from conception to adulthood. It is useful to distinguish between early child development programs that focus on care provided by others (e.g., high quality child care) and programs that specifically target parents and support the parenting role. The early focus on the first thousand days has been expanded to address the evidence of a 'fade out' of such early interventions [14]. A key implication of these recommendations is to increase global access to evidence-based parenting support (EBPS) which refers to a broad range of scientifically supported parenting interventions that can form a comprehensive population-based approach to optimally supporting parents and children. Such a public health approach blends universal and targeted program components for both the prevention and treatment of social, emotional and behavioral problems in childhood.

\section{The Evidence on Parenting Support}

EBPS programs based primarily on social learning theory, cognitive-behavioral principles and developmental science hold great potential in modifying family risk and protective factors. The approach typically involves forming a collaborative relationship with a parent and providing clear guidance and support, using methods such as modelling, practice and feedback to enhance specific parenting skills. Five core principles of positive parenting have been shown to be cross-culturally robust in promoting children's development [15]. These are: (i) creating a safe, nurturing and engaging home environment, (ii) creating a responsive, positive learning environment, (iii) providing assertive and consistent boundaries and discipline, (iv) having reasonable expectations of children and oneself as a parent, and (v) having the capacity for self-care in the parenting role.

A substantial body of empirical work has established that EBPS programs employing these principles are effective in diverse cultural and service contexts and populations [e.g. 16-18]. Multiple systematic reviews and meta-analyses have shown that EBPS programs influence a variety of outcomes including enhancing parental skills and mental health [19], child emotional and behavioural adjustment and social 
competencies [20,21], academic attainment [22], physical health [23]; and prevention of child maltreatment and family violence [24]. Programs range from brief ( $2-4$ sessions) to more intensive $(20+$ sessions $)$, and have small to very large effect sizes depending on population and outcome measurement.

A systematic global agenda for parenting support necessitates the inclusion of a population health approach that "emphasizes the targeting of parents at a whole-of-population level, utilizing a blend of universal and targeted interventions, to achieve meaningful change in population-level indices of child and parent outcomes" [25], p. 339]. This approach includes balancing targeted and universal intervention proportionate to need. This principle, called proportionate universalism [26], recognizes that programs, services, and policies must include a range of responses to address different levels of need and disadvantage within the population. The Nurturing Care Framework [13] uses this type of approach (see Fig. 2).

Inclusion of a universal EBPS approach seeking to address generic parental concerns would benefit all parents in a given population, rather than focusing solely on intensive, tertiary level intervention for a small percentage of vulnerable parents struggling with chronic or clinically diagnosable issues relating to their child's social, emotional, behavioral or developmental health. By providing support according to need, all families can gain access, population prevalence rates can shift as cases are averted, and tertiary services remain available for those in need of intensive interventions.
Randomized controlled trials of EBPS have been conducted in not only Western countries such as the US, Canada, Australia, New Zealand, and Europe (UK, Ireland, Germany, Belgium, France, Switzerland, the Netherlands, Sweden, Norway, Denmark) but also in Asia (Japan, China, Indonesia, Singapore), Latin America (Panama, Chile), the Middle East (Turkey, Iran) and Africa (South Africa) [27, 28]. Over 20 years ago, Forehand and Kotchick [29] called for culturally responsive parenting interventions to meet the goals and values of minority groups within mainstream cultures. Although there is still little evidence that ethnicity itself is a moderator of EBPS outcomes or satisfaction, culturally specific adaptations have shown comparable outcomes to the original programs [30], and can significantly improve family engagement and retention [31]. Contrary to concerns that Western programs may not be generalizable to diverse country contexts, a meta-analysis of cross-country translation of EBPS interventions (with little or no adaptation) showed them to be equally, if not more, effective when transported to populations and countries that are culturally different from where the programs originated [32]. Country-level policy and resource factors (e.g., poverty) do not seem to be associated with intervention effectiveness and there is small but growing evidence of parenting programs implemented in developing countries [33]. If we are to increase access to EBPS, the tension between fidelity to proven programs and flexibility in adaptation is important but not insurmountable, and more nuanced thinking about cultural adaptation moving from a dichotomous 'either fidelity-or-adaptation' perspective to an inclusive 'both fidelity and adaptation' approach can be effective [34]. The following case studies describe the adaptation

\section{MEETINC FAMILIES' AND CHILDREN'S NEEDS}

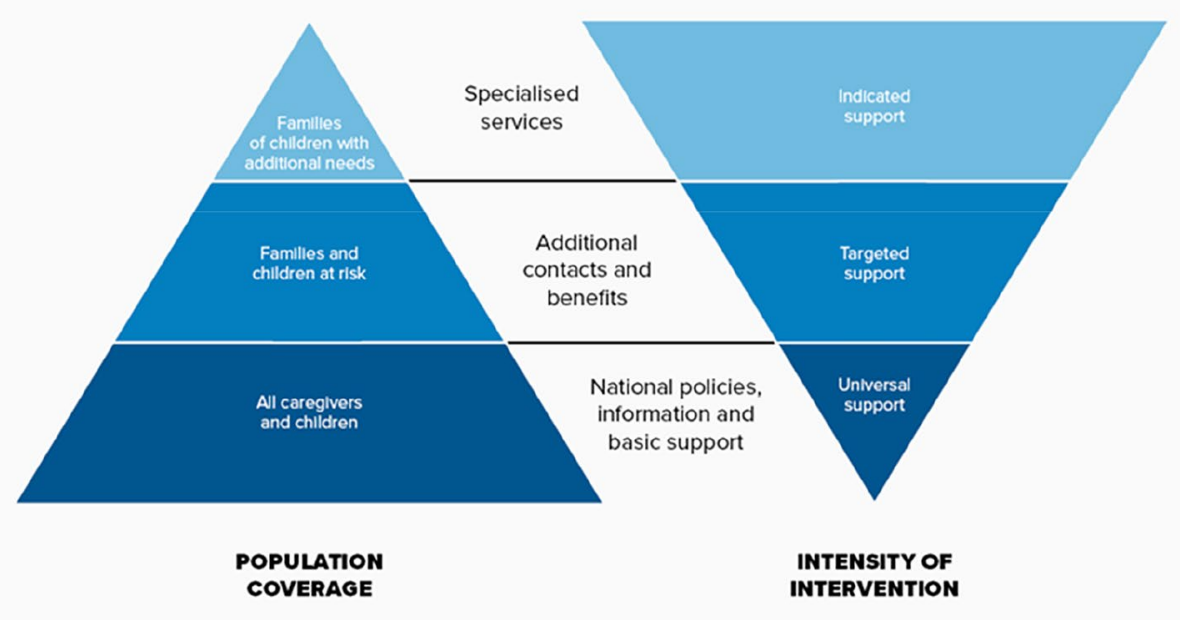

Fig. 2 Nuturing care framework for evidence-based parenting support 
of universal and targeted parenting interventions for use in diverse contexts (see below).

\section{Adapting Evidence-Based Parenting Interventions for Diverse Contexts: Two Case Studies}

\section{Universal Intervention: Triple P: Adapting an Australian Positive Parenting Program Globally}

Triple $\mathrm{P}$ has a growing international evidence base [35], which has been underpinned by a collaborative participation adaptation model (CPAM) used to assess the cultural and contextual fit of a program, and inform any tailoring required to ensure optimal engagement and outcomes [36]. The CPAM is focused on partnering with local stakeholders to pilot existing programs with no or surface-level adaptation and receive practitioner and community feedback about program adaptation requirements in relation to language, content, and delivery. One example is an RCT of a brief 2-hour Triple P discussion group (Dealing with Disobedience) in Panama [34] with a minimally adapted protocol (i.e. surface level changes including language translation and local examples delivered by a Panamanian facilitator). Retention and parent-reported outcome results paralleled those found with higher SES Western samples, including reduced dysfunctional parenting and parental stress, and fewer child behavior difficulties in comparison to waitlist control families. In another example, two Triple P discussion groups (Being a Positive Parent and Dealing with Disobedience) were trialled in New Zealand, where an initial pilot informed community consultation with a Māori iwi (tribe) elders, parents and local health practitioners. Deeper level cultural adaption was recommended involving the development of two adjunct resources relating to Māori values, to augment Triple $\mathrm{P}$ delivery by Māori facilitators [37]. Families reported high satisfaction with the adapted program and, in comparison to control families, greater reductions in over-reactive parenting practices and inter-parental conflict, and greater improvements in parenting confidence and child behavior.

\section{Targeted interventions: From PACT to PASS: Parenting Interventions for Autism from the UK to South Asia}

A systematic approach was used to adapt an evidence-based parent-mediated intervention for autism in two South Asian settings (Goa, India and Rawlpindi, Pakistan). Preparing the intervention for delivery in new contexts involved a stepwise iterative process [38-40] A fundamental step was bringing together the voices of key stakeholders (including parents of children with autism, parents who had experienced the intervention as practice cases, special educators, speech and language therapists and developmental paediatricians) in order to explore the acceptability of intervention components. This allowed the teams to consider and address key concerns during the adaption process, including the use of language and metaphors to support delivery with low literacy populations, and the development of suitable practice materials for use by non-specialist providers. A key to intervention effectiveness in two pilot trials has been the development of measures to gauge the quality of the sessions delivered, an objective competency measure to evaluate the knowledge and skills of non-specialist lay counsellors delivering the intervention, and a supportive supervisory framework to sustain lay counsellors in their new roles [41].

\section{Implementing Parenting Programs Globally}

There is widespread recognition of the importance of parenting support by global policy advocacy groups (WHO, UNODC, UNICEF) and a clear need based on epidemiological surveys of corporal punishment and family violence, and longitudinal studies documenting the adverse effects of corporal punishment on children. However, the reality is that EBPS programs have not been integrated and mainstreamed into public health and social welfare programs in most countries, and certainly not in any LMIC. The vast majority of the world's population of children who might benefit from their parents participating in EBPS live in countries where such programs are simply not a policy priority [42].

Scaling interventions that work is difficult when there are very limited financial resources to invest in workforce development and resources. In such contexts, low priority is given to parenting support compared to other areas of health. Apart from the lack of funds to support research on parenting that would build a local evidence base, there are additional major challenges that must be addressed before significant progress can be made in scaling up EBPS programs. These challenges include complexity of interventions, lack of human resources, issues with progam fidelity, low demand within the health and family welfare sectors to incorporate such interventions (due largely to lack of awareness of EBPS and potential stigma in relation to help seeking), and lack of sustainable models to ensure financial resources for interventions. Each of these factors is explored further below.

The complexity of parenting interventions may be addressed through the design of lean interventions which emphasize the 'active ingredients' of EBPS. Meta-analysis has demonstrated that the constituent parts of multi-component EBPS interventions can have differential effectiveness. A review of 77 published studies of EBPS programs found that increasing positive parent-child interactions and 
emotional communication skills, as well as teaching parents the importance of parenting consistency and the use of nonescalatory discipline strategies such as time-out, were associated with relatively larger effects on measures of parenting behaviors and children's behavior problems after controlling for differences in research design [43]. Further dismantling studies are needed to establish how key ingredients may be combined optimally within lean intervention packages, which could be optimally scalable. Such 'common elements' based approaches and brief interventions are gaining traction in other domains of behavioral interventions [44].

A common strategy for overcoming the lack of specialist providers of psychosocial interventions is the redeployment of community health workers and other paraprofessionals [39] and parents [40]. However, sustaining the workforce involved in such task sharing models is a frequently cited problem [45]. Some EBPS program developers have looked at ways to increase long-term commitment and retention among non-specialist providers by emphasizing developmental opportunities and the enhanced community status afforded by their role. For example, the Empowering Parents, Empowering Communities (EPEC) program, originally developed for disadvantaged families in the UK, incorporates a peer-led delivery model whereby providers ('peer facilitators') are selected based on prior experience as participants in EPEC parenting groups [46]. This innovation ensures that knowledge and skills are reinforced and not 'lost' at the end of each commissioned EPEC project, since peer facilitators commonly reside within local communities [47].

The challenge of assuring fidelity of scaled-up parenting interventions can be addressed by emphasizing the role of community members to monitor the quality of delivery. Recent work in South Africa [48] has shown that 'community facilitators' without prior training and knowledge of EBPS were able to deliver a manualized program with a high degree of fidelity, and competence appeared to increase as these providers gained more experience. However, an extended period of supervised practice may not be feasible in settings where specialist supervision is scarce or nonexistent, and funding limitations and high demand for services do not allow for a gradual period of embedding for novice providers. Digitally supported and peer-led supervision offer promising avenues for overcoming such resource constraints, with indications that non-specialist providers of psychological therapies can be trained to assess therapy quality to the same degree of reliability as experts [41].

Low demand for parenting programs can be addressed through powerful mass media and communication strategies that promote, normalize and destigmatize parental participation by highlighting the benefits of EBPS to children and their families [49]. Public health strategies such as the use of peer champions, respected professional advocates, and greater use of flexible delivery formats to make participation more convenient (e.g. brief programs, online delivery) can also boost participation rates. Alternative delivery systems can be explored to minimize cost, particularly for universal interventions. These include the use of broadcast television programs [50] and radio programs or podcasts [51] online or mobile app based parenting interventions [52] large and small group preventive seminars and workshops [37], and more intensive multi-session group and individual programs for families with complex needs [25]. The most cost-effective modalities to date involve online and groupbased delivery. However, rigorous programs of research are needed to test the efficacy, effectiveness and feasibility of different program delivery formats and modalities in different resource contexts.

In wealthier countries, the most widely disseminated EBPS programs are based on the development of an economically sustainable model of scaling that has involved named programs and the commercialization of professional training, resources and materials [53]. Most programs have a publisher or purveyor organization that is licensed (typically by the University that owns the intellectual property vested in the program) to publish practitioner and parent resources, conduct professional training, and offer technical and implementation support. This situation has arisen out of necessity as research grants typically fund early-stage evaluations but not the dissemination of proven programs following foundational trialling. Programs such as Incredible Years, Triple P, and Family Check-Up have all developed business models that enable dissemination activity to become self-sustaining. Some disseminators (e.g., Triple P International) have acquired bCorp status as a social enterprise and have established not-for-profit arms (Families Foundation). However, commercially published parenting programs have been criticized as being expensive and beyond the resources of most LMICs. While there is considerable evidence that existing (commercial) EBPS programs can be tailored to fit culturally diverse and low-resource contexts, innovation in low-cost service delivery formats and venues is ongoing. Organizations such as WHO and UNICEF have also developed their own open access programs (e.g., Parenting for Lifelong Health [54]), and as their evidence is emerging it will be essential that the true costs of various models are evaluated, to allow direct comparison of these various EBPS approaches. Accurate cost projections would allow communities to adequately cost and plan for program sustainability.

In many countries, the mandate for parenting programs falls across several ministries and can lead to disjointed planning and funding decisions. For example, in India, parenting programs potentially fall under the remit of a large number of ministries, including the ministries of Women and Child Development, Health and Family Welfare, Human Resource Development, and Social Justice and Empowerment; 
Table 2 Child and parent/carer life skills developed through parenting interventions

Children and young people

1. Positive family relationships skills (parents, siblings, grandparents, step parents, kinship carers)

2. Healthy relationships with peers and significant others (teachers, tutors, coaches, instructors)

3. Good language and communication skills (expressive and receptive language, vocabulary, writing skills, technology literacy)

4. Intellectual skills (executive function, attention, memory, learning, curiosity, creative thinking, reasoning and problem solving)

5. Emotional resilience (stress management and anxiety coping skills, thankfulness and contentment, mental health literacy and appropriate help-seeking behaviour)

6. Independence and self-care skills (toileting, hygiene, dressing, brushing teeth, using public transport, use of computers, study skills, problem solving)

7. Compassion (being aware, empathic, socially responsible, helpful, kind, tolerant, mindful and compassionate towards self and others, avoiding being a bystander towards bullying, cyberbullying, racism, and sexism)

8. Healthy habits (adequate sleep, limited screen time, healthy diet, physically activity)

9. Environmental responsibility (reduced energy and excess water consumption, waste disposal), avoiding being a perpetrator or bystander to environmental destruction, being disaster prepared)

10. Cultural connection (being aware of and valuing cultural heritage, traditions (music, dance, theatre, art), celebrating rituals, language, family history)
Parents/carers

1. Ensuring a safe, secure, caring and non-violent home (child safe homes, cyber-safety, supervision)

2. Facilitating children's friendships and positive relationships with significant others (siblings, peers, kinship carers, extended family, sports coaches, tutors, instructors), including positive social interaction and respect

3. Creating a positive, interesting and responsive learning environment (language, communication, books and literacy, numeracy, executive function, attention, memory, delaying gratification, impulsivity, problem solving)

4. Having reasonable, developmentally appropriate expectations of children and realistic personal expectations

5. Helping children self-regulate their emotions and behavior through limit setting

6. Self-care as a parent/carer (managing emotions, taking care of relationships, self-compassion, coping with the past, developing healthy habits, having healthy work-life balance, manage finances, planning for the future)

7. Promoting acceptance, tolerance, and compassion towards others

8. Creating a healthy home (clean air, water, sanitation, healthy habits, healthy food, plenty of physical activity, dental care)

9. Taking environmentally responsible family actions that protect the ecosystem and animals of the world

10. Taking responsible family actions that promote tolerance and acceptance (anti-discrimination relating to ethnicity, gender), gender equity, social justice and social inclusion, and cultural pride underpinning these is the Finance ministry which allocates budgetary provisions. This fractured mandate means that the linking together of the needs of children and their families at every age and stage of parenting is not addressed, and the responsibility for delivery of EBPS across developmental transitions is not clear. However, multi-sector initiatives can serve as models, such as Healthy Child Manitoba in Canada, a cross-departmental strategy (including Education and Training, Families, Health, Seniors and Active Living, Indigenous and Northern Relations, Justice, Sustainable Development and Status of Women) which developed a network of strategies for children, youth and families.

A risk is that new or unsupported programs may be disseminated widely before there is sufficient evidence for their effectiveness. Evaluation of impact needs validated measurement tools that ensure appropriate baseline assessment to match target concerns to intervention intensity, and systematic assessment of outcomes following interventions. Use of psychometrically sound, change-sensitive, cross-culturally validated tools is crucial for assessing parenting and family well-being constructs and child development and mental health outcomes at at an individual and population level. The tools in current use in parenting research, however, do not meet these criteria [55]. The available, largely self-report, measures tend to be long, use confusing scoring formats, have high literacy demands, and typically do not specifically measure the proximal intervention targets that are addressed by many EBPS interventions (e.g. use of praise and contingent positive attention, use of rules and consequences). Some (e.g., Eyberg Child Behavior Inventory, Child Behavior Checklist) are proprietry in nature and hence not feasible for low-resource contexts. There needs to be ongoing effort to develop a globally applicable, change sensitive and scalable assessment of parenting practices targeted by EBPS and concomitant child outcomes. Measures such as the International Parenting Survey show promise as a brief reliable measure of parenting practices and family well-being [56]. However, additional items related to ecologically sustainable living and other SDGs are needed (e.g. waste disposal, water consumption, use of clean energy). Considerable work is needed to enable population-based survey measures to be linked with various administrative data sets (e.g. child maltreatment, hospitalization and injuries, out-of-home placement, family violence, educational attainment) held by governments to track population-level change.

\section{Expanding the Focus of Parenting Skills Interventions}

The development of prosocial and emotional competencies in children has been the primary focus of many EBPS programs. However, principles and strategies of positive 
parenting can be applied to a wider range of developmental capabilities and life skills that have direct relevance to attaining multiple SDGs. Table 2 summarizes the developmental capabilities of children, young people and parents/carers that can be developed through parenting programs and applied to different SDGs. The benefits of parenting interventions are fundamentally intergenerational. For each developmental capability in children there are reciprocal and/or complementary capabilities in adults can develop through interactions with children and young people (see Table 2).

\section{Combining Parenting, School and Community-Based Interventions}

The mobilation of population level change may be easier to accomplish when families, schools and the wider community harmonize their approach to the attainment of SDGs. Schools provide a universal access point for engaging both children and parents. An online curriculum that provides teachers with digital tools, projects and ideas to provide engaging learning activities for students related to SDGs would also provide a context for parental involvement. Specific parenting skills and strategies to support ecologically sustainable family and community living would complement and support the knowledge and skills children acquire at school. Furthermore, schools could outreach to the wider community to get sponsors or "in kind" support for their positive efforts to transform their local community. The synergistic bringing together of home, school and community drivers of change focused on creating healthier and more productive futures for children can be evaluated as a "placebased" intervention.

\section{Parenting Support in the Context of a Global Pandemic}

The COVID-19 pandemic has not only been a major global threat to human life, it has had a pervasive impact on the mental health, education and the overall wellbeing of children, young people and their families [57] The ecomonic consequences of the pandemic have been serious and many more families have slipped into poverty $[58,59]$. The pandemic has posed major challenges to the delivery of existing EBPS programs, such that lockdowns and social distancing have disrupted "in person" delivery of services and also the training of practitioners and support of organizations delivering parenting programs. Compensatory strategies include the widespread use of telehealth and online platforms to deliver parenting programs, the development of tailored materials to address COVID-19-related parenting challenges (e.g., dedicated downloadable resources and podcast and television series such as Parenting in a Pandemic; https://pfsc.psychology.uq.edu.au/covid19-resources), and the rapid transition to videoconferencing as a method of training practitioners [60]. In a similar move, the WHO / UNICEF Parenting for Lifelong Health online resources, which are avaible in a hundred languages, now include COVID-specific parenting advice (https://www.covid19par enting.com/home). Evaluations of remotely delivered innovations suggest strong potential for impact. Comparable results have been found for online videoconference-based and in-person practitioner training [61] and parenting interventions $[62,63]$. These promising findings suggest that online programs can markedly increase the global reach of EBPS in the future. Further, at a time when face-to-face social connections are severely restricted, there is also a need to examine how virtual groups can be harnessed to promote engagement and positive outcomes for parenting interventions. These directions may also help to lower the cost, and extend the reach and impact of EBPS in the future.

Globally there is a significant cumulative cost for inaction and failure to promote better parenting of children and young people through EBPS. These costs include increased risk of child maltreatment, severe and persistent mental health problems, poorer physical health and substance abuse problems, intergenerational poverty, gender ineqiuality, and lost life potential.

\section{Summary}

Substantial progress towards the achievement of SDGs will occur when scientific knowledge about how to achieve behavior change at a population level becomes an integral part of global multidisciplinary efforts to create a healthier, more humane, just and ecologically sustainable world. We make a case for a systematic global policy and research agenda for scaling up parenting interventions, arguably amongst the most effective yet neglected behavioral interventions for attaining the SDGs. Positive parenting has the potential to become a common pathway to promote a diverse range of prosocial outcomes in both children and adults and, with foundational social and emotional competencies in place, move rapidly towards the ultimate goal of building of a healthier and more economically productive life course. The proactive mobilization of families through positive parenting can support other global and local policybased initiatives designed to ensure a more inclusive and equitable future for all. This includes recommendations on: (1) combining universal and targeted approaches, (2) the critical need for essential content and contextual adaptation, (3) designing parenting interventions with a view to their 
scalability, (4) the need for a multi-sectoral approach, (5) considerations for adequate resourcing, and (6) the development of scalable measures for assessment of impact. An ambitious implementation research agenda is needed to investigate how changing parenting practices can create new lifecourse opportunities and societal impact across generations. This knowledge underpins the conceptual and scientific rationale for arguing that EBPS should become an essential part of any country's plan to achieve the United Nation's Sustainable Developmental Goals.

Supplementary Information The online version contains supplementary material available at https://doi.org/10.1007/s10578-021-01171-0.

Author Contributions All authors contributed to the conception and writing of this work and approved the final manuscript.

Funding This work was supported through strategic funding awarded by the Vice Chancellor of the University of Queensland.

\section{Declarations}

Conflict of interest The Triple P-Positive Parenting Program is developed and owned by The University of Queensland (UQ). The university, through its main technology transfer company UniQuest Pty Ltd, has licensed Triple P International Pty Ltd (TPI) to publish and disseminate the program worldwide. Royalties from this dissemination activity are distributed to the UQ Faculty of Health and Behavioural Sciences, Parenting and Family Support Centre and contributory authors. MS and KT are contributory Triple $\mathrm{P}$ authors and receive royalties from TPI. The other authors are independent from Triple P. No authors of this paper have any share or ownership of TPI, and TPI had no involvement in the development of this report. DM has previously been involved in the evaluation and dissemination of the Empowering Parents, Empowering Communities (EPEC) parenting intervention developed by the Centre for Parent and Child Support, South London and Maudsley NHS Foundation Trust. He has no share or ownership of EPEC and does not receive any royalties or other fees related to this or any other parenting intervention. GD, MSing, RV and VP have no conflicts to declare.

Ethical Approval This article does not contain any studies with humans or animals performed by any of the authors.

\section{References}

1. The World Bank Group (2019) Population ages 0-14 (\% of total population). https://data.worldbank.org/indicator/SP.POP.0014. TO.ZS

2. Lu C, Black MM, Richter LM (2016) Risk of poor development in young children in low-income and middle-income countries: an estimation and analysis at the global, regional, and country level. Lancet Glob Health 4(12):916-922. https://doi.org/10.1016/ S2214-109X(16)30266-2

3. Sanders MR, Turner KMT (2018) The importance of parenting in influencing the lives of children. In: Sanders MR, Morawska A, eds. Handbook of Parenting and Child Development Across the Lifespan. New York: Springer pp. 3-26
4. Clark H, Coll-Seck AM, Banerjee A, Peterson S, Dalglish SL, Ameratunga S et al (2020) A future for the world's children? A WHO-UNICEF-Lancet Commission. Lancet 395(10224):605658. https://doi.org/10.1016/S0140-6736(19)32540-1

5. Gershoff ET, Grogan-Kaylor A (2016) Spanking and child outcomes: Old controversies and new meta-analyses. J Fam Psychol 30(4):453-469. https://doi.org/10.1037/fam0000191

6. Felitti VJ, Anda RF, Nordenberg D, Williamson DF, Spitz AM, Edwards E et al (1998) Relationship of childhood abuse and household dysfunction to many of the leading causes of death in adults: The Adverse Childhood Experiences (ACE) Study. Am J Prev Med 14(4):245-258. https://doi.org/10.1016/S07493797(98)00017-8

7. Shonkoff JP (2012) Leveraging the biology of adversity to address the roots of disparities in health and development. PNAS USA 109(2):17302-17307. https://doi.org/10.1073/pnas.1121259109

8. Sanders MR, Mazzucchelli TG. How parenting influences the lives of children. In: Sanders MR, Mazzucchelli TG, eds (2018) The Power of Positive Parenting: Transforming the Lives of Children, Parents, and Communities using the Triple P System. New York: Oxford University Press pp. 5-31

9. UNICEF Office of Research - Innocenti (2018) Key Findings on Families, Family Policy and the Sustainable Development Goals: Synthesis Report. UNICEF, Florence, Italy

10. Velleman R, Templeton LJ (2018) Impact of parents' substance misuse on children: an update. BJPsych Adv 22(2):108-117. https://doi.org/10.1192/apt.bp.114.014449

11. Rutherford HJV, Wallace NS, Laurent HK, Mayes LC (2015) Emotion regulation in parenthood. Dev Rev 36:1-14. https://doi. org/10.1016/j.dr.2014.12.008

12. Sanders MR, Turner KMT, Metzler CW (2019) Applying selfregulation principles in the delivery of parenting interventions. Clin Child Fam Psychol Rev 22(1):24-42. https://doi.org/10.1007/ s10567-019-00287-z

13. World Health Organization, United Nations Children's Fund, World Bank Group (2018) Nurturing Care for Early Childhood Development: A Framework for Helping Children Survive and Thrive to Transform Health and Human Potential. World Health Organization, Geneva, Switzerland

14. Bailey D, Duncan GJ, Odgers CL, Yu W (2017) Persistence and fadeout in the impacts of child and adolescent interventions. J Res Educ Eff 10(1):7-39. https://doi.org/10.1080/19345747.2016. 1232459

15. Morawska A, Sanders M, Goadby E et al (2011) Is the Triple P-Positive Parenting Program acceptable to parents from culturally diverse backgrounds? J Child Fam Stud 20(5):614-622. https://doi.org/10.1007/s10826-010-9436-X

16. Michelson D, Davenport C, Dretzke J, Barlow J, Day C (2013) Do evidence-based interventions work when tested in the "real world?" A systematic review and meta-analysis of parent management training for the treatment of child disruptive behavior. Clin Child Fam Psychol Rev 16(1):18-34. https://doi.org/10.1007/ s10567-013-0128-0

17. Spencer CM, Topham GL, King EL (2020) Do online parenting programs create change?: A meta-analysis. J Fam Psychol 34(3):364-374. https://doi.org/10.1037/fam0000605

18. Ruane A, Carr A (2019) Systematic review and meta-analysis of Stepping Stones Triple P for parents of children with disabilities. Fam Process 58(1):232-246. https://doi.org/10.1111/famp.12352

19. Furlong M, McGilloway S, Bywater T, Hutchings J, Smith SM, Donnelly M (2012) Behavioural and cognitive-behavioural groupbased parenting programmes for early-onset conduct problems in children aged 3 to 12 years. Cochrane Database Syst Rev 2:1-239. https://doi.org/10.1002/14651858.CD008225.pub2

20. Barlow J, Bergman H, Kornør H, Wei Y, Bennett C (2016) Groupbased parent training programmes for improving emotional and 
behavioural adjustment in young children. Cochrane Database Syst Rev 8:1-127. https://doi.org/10.1002/14651858.CD003680. pub3

21. England-Mason G, Gonzalez A (2020) Intervening to shape children's emotion regulation: A review of emotion socialization parenting programs for young children. Emotion 20(1):98-104. https://doi.org/10.1037/emo0000638

22. Brennan LM, Shelleby EC, Shaw DS, Gardner F, Dishion TJ, Wilson M (2013) Indirect effects of the family check-up on school-age academic achievement through improvements in parenting in early childhood. J Ed Psychol 105(3):762-773. https://doi.org/10.1037/ a0032096

23. Morawska A, Mitchell A, Mihelic M (2020) A systematic review of parenting interventions for child chronic health conditions. $\mathrm{J}$ Child Health Care 24(4):603-628. https://doi.org/10.1177/13674 93519882850

24. Chen M, Chan KL (2016) Effects of parenting programs on child maltreatment prevention: a meta-analysis. Trauma Violence Abuse 217(1):88-104. https://doi.org/10.1177/15248 38014566718

25. Sanders MR, Kirby JN, Tellegen CL, Day JJ (2014) The Triple P-Positive Parenting Program: a systematic review and meta-analysis of a multi-level system of parenting support. Clin Psychol Rev 34(4):337-357. https://doi.org/10.1016/j.cpr.2014.04.003

26. Marmot M, Bell R (2016) Fair society, healthy lives. Public Health 126(Suppl 1):S4-S10. https://doi.org/10.1016/j.puhe.2012.05.014

27. Kumpfer KL, Magalhães C, Xie J (2017) Cultural adaptation and implementation of family evidence-based interventions with diverse populations. Prev Sci 18(6):649-659. https://doi.org/10. 1007/s11121-016-0719-3

28. Turner KMT, Singhal M, McIlduff C, Singh S, Sanders MR (2020) In: Fvd Vijver, Halford WK (eds) Evidence-based parenting support across cultures: The Triple P - Positive Parenting Program experience. Cross-cultural Family Research and Practice, New York, Elsevier, pp 603-644. https://doi.org/10.1016/B9780-12-815493-9.00019-3

29. Forehand R, Kotchick BA (1996) Cultural diversity: A wake-up call for parent training (republished article). Beh Ther 47(6):981992. https://doi.org/10.1016/j.beth.2016.11.010

30. Ortiz C, Del Vecchio T (2013) Cultural diversity: Do we need a new wake-up call for parent training. Beh Ther 44(3):443-458. https://doi.org/10.1016/j.beth.2013.03.009

31. United Nations Office on Drugs and Crime (2009) Guide to Implementing Family Skills Training Programmes for Drug Abuse Prevention. UNODC, New York

32. Gardner F, Montgomery P, Knerr W (2016) Transporting evidence-based parenting programs for child problem behavior (age 3-10) between countries: Systematic review and meta-analysis. J Clin Child Adolesc Psychol 45(6):749-762. https://doi.org/10. 1080/15374416.2015.1015134

33. Mejia A, Calam R, Sanders MR (2012) A review of parenting programs in developing countries: opportunities and challenges for preventing emotional and behavioral difficulties in children. Clin Child Fam Psychol Rev 15(2):163-175. https://doi.org/10. 1007/s10567-012-0116-9

34. Mejia A, Calam R, Sanders MR (2015) A pilot randomized controlled trial of a brief parenting intervention in low-resource settings in Panama. Prev Sci 16(5):707-717. https://doi.org/10.1007/ s11121-015-0551-1

35. Sanders MR, Mazzucchelli TG (eds) (2018) The Power of Positive Parenting: Transforming the Lives of Children, Parents, and Communities using the Triple P System. Oxford University Press, New York

36. Turner KMT, Sanders MR, Keown LJ, Shepherd M (2018) A collaborative participation adaptation model. In: Sanders MR, Mazzucchelli TG (eds) The Power of Positive Parenting: Transforming the Lives of Children, Parents, and Communities using the Triple P System. Oxford University Press, New York, pp 310-320

37. Keown LJ, Sanders MR, Franke N, Shepherd M (2018) Te Whānau Pou Toru: A randomized controlled trial (RCT) of a culturally adapted low-intensity variant of the Triple P-Positive Parenting Program for indigenous Māori families in New Zealand. Prev Sci 19(7):954-965. https://doi.org/10.1007/s11121-018-0886-5

38. Divan G, Hamdani SU, Vajartkar V, Minhas A, Taylor c, Aldred $\mathrm{C}$, et al (2015) Adapting an evidence-based intervention for autism spectrum disorder for scaling up in resource-constrained settings: the development of the PASS intervention in South Asia. Glob Health Action 8:1. https://doi.org/10.3402/gha.v8.27278

39. Divan G, Vajaratkar V, Cardozo P, Huzurbazar S, Verma M, Howarth E et al (2019) The feasibility and effectiveness of PASS Plus, a lay health worker delivered comprehensive intervention for autism spectrum disorders: Pilot RCT in a rural low and middle income country setting. Autism Res 12(2):328-339. https://doi. org/10.1002/aur.1978

40. Rahman A, Divan G, Hamdani SU, Vajaratkar V, Taylor C, Leadbitter K et al (2016) Effectiveness of the parent-mediated intervention for children with autism spectrum disorder in south Asia in India and Pakistan (PASS): a randomised controlled trial. Lancet Psychiatry 3(2):128-136. https://doi.org/10.1016/S2215-0366(15) 00388-0

41. Singla DR, Weobong B, Nadkarni A, Chowdhary N, Shinde S, Anand A et al (2014) Improving the scalability of psychological treatments in developing countries: an evaluation of peer-led therapy quality assessment in Goa, India. Beh Res Ther 60:53-59. https://doi.org/10.1016/j.brat.2014.06.006

42. Ward C, Sanders MR, Gardner F, Mikton C, Dawes A (2016) Preventing child maltreatment in low- and middle-income countries: Parent support programs have the potential to buffer the effects of poverty. Child Abuse Negl 54:97-107. https://doi.org/10.1016/j. chiabu.2015.11.002

43. Kaminski JW, Valle LA, Filene JH, Boyle CL (2008) A metaanalytic review of components associated with parent training program effectiveness. J Abnorm Child Psychol 36(4):567-589. https://doi.org/10.1007/s10802-007-9201-9

44. Singla DR, Kohrt BA, Murray LK, Anand A, Chorpita BF, Patel V (2017) Psychological treatments for the world: Lessons from lowand middle-income countries. Annu Rev Clin Psychol 13:149181. https://doi.org/10.1146/annurev-clinpsy-032816-045217

45. Padmanathan P, De Silva MJ (2013) The acceptability and feasibility of task-sharing for mental healthcare in low and middle income countries: A systematic review. Soc Sci Med 97:82-86. https://doi.org/10.1016/j.socscimed.2013.08.004

46. Day C, Michelson D, Thomson S, Penney C, Draper L (2012) Evaluation of a peer led parenting intervention for disruptive behaviour problems in children: Community based randomised controlled trial. BMJ 344:1-10. https://doi.org/10.1136/bmj.e1107

47. Thomson S, Michelson D, Day C (2015) From parent to "peer facilitator": A qualitative study of a peer-led parenting programme. Child Care Health Dev 41(1):76-83. https://doi.org/10. $1111 /$ cch. 12132

48. Lachman JM, Kelly J, Cluver L, Ward CL, Hutchings J, Gardner F (2018) Process evaluation of a parenting program for low-income families in South Africa. Res Soc Work Pract 28(2):188-202. https://doi.org/10.1177/1049731516645665

49. Wilkinson L (2018) Using social marketing strategies to increase program reach. In: Sanders MR, Mazzucchelli TG, eds. The Power of Positive Parenting: Transforming the Lives of Children, Parents, and Communities using the Triple P System. New York, Oxford University Press, pp.383-394

50. Calam R, Sanders MR, Miller C, Sadhnani V, Carmont SA (2008) Can technology and the media help reduce dysfunctional parenting and increase engagement with preventative parenting 
interventions? Child Maltreat 13(4):347-361. https://doi.org/10. $1177 / 1077559508321272$

51. Morawska A, Tometzki H, Sanders MR (2014) An evaluation of the efficacy of a Triple P-Positive Parenting Program podcast series. J Dev Behav Pediatr 35(2):128-137. https://doi.org/10. 1097/DBP.0000000000000020

52. Sanders MR, Baker S, Turner KMT (2012) A randomized controlled trial evaluating the efficacy of Triple P Online with parents of children with early-onset conduct problems. Beh Res Ther 50(11):675-684. https://doi.org/10.1016/j.brat.2012.07.004

53. Crane ME, Kendall PC, Chorpita BF, Sanders MR, Mille AR, Webster-Stratton C, et al (under review). The role of international dissemination and implementation organizations in scaling psychological interventions.

54. Ward CL, Wessels IM, Lachman JM, Hutchings J, Cluver LD, Kassanjee R et al (2020) Parenting for Lifelong Health for Young Children: a randomized controlled trial of a parenting program in South Africa to prevent harsh parenting and child conduct problems. J Child Psychol Psychiatry 61(4):503-512. https://doi.org/ 10.1111/jcpp. 13129

55. Morawska A, Sanders MR (2018) Measuring child, parent and family outcomes at individual and population levels. In: Sanders MR, Mazzucchelli TG, eds. The Power of Positive Parenting: Transforming the Lives of Children, Parents, and Communities using the Triple P System. New York, Oxford University Press, pp 395-404

56. Morawska A, Filus A, Haslam D, Sanders MR (2019) The International Parenting Survey: Rationale, development and potential applications. Compr Child Adolesc Nurs 42(1):40-53. https://doi. org/10.1080/24694193.2017.1384082

57. Patrick SW, Henkhaus LE, Zickafoose JS, Lovell K, Halvorson A, Loch S et al (2020) Well-being of parents and children during the COVID-19 pandemic: a national survey. Pediatrics. https:// doi.org/10.1542/peds.2020-016824
58. Pak A, Adegboye OA, Adekunle AI, Rahman KM, McBryde ES, Eisen DP (2020) Economic consequences of the COVID-19 outbreak: The need for epidemic preparedness. Front Public Health 8:1-4. https://doi.org/10.3389/fpubh.2020.00241

59. Martin A, Markhvida M, Hallegatte S, Walsh B (2020) Socioeconomic impacts of COVID-19 on household consumption and poverty. Econ Disaster Clim Chang 4(3):453-479

60. Sanders MR, Turner KMT, Cobham, VE, McWilliam J, Ralph A, Mazzucchelli TG (under review) The Parenting in a Pandemic response strategy to address the emotional consequences of COVID-19: Developer and purveyor perspectives.

61. Sanders MR, Hoang, NPT, Gerrish RJ, Ralph A, McWilliam J (under review) A large-scale evaluation of a system of professional training for the Triple P- Positive Parenting Program: effects of practitioner characteristics, type of training, country location and mode of delivery on practitioner outcomes.

62. Prinz RJ, Metzler, CM, Sanders MR, Rusby JC, Chao C (under review) Online-delivered parenting intervention for young children with disruptive behavior problems: A non-inferiority trial focused on child and parent outcomes.

63. Day JJ, Baker S, Dittman CK., Franke N, Hinton S, Love S, Sanders MR, Turner KMT (under review) Predicting positive outcomes and successful completion in an online parenting program for parents of children with disruptive behavior: An integrated data analysis.

Publisher's Note Springer Nature remains neutral with regard to jurisdictional claims in published maps and institutional affiliations. 